\title{
Adenomyosis: Pictorial Essay of Two-Dimensional and Three-Dimensional Ultrasonography Findings
}

\author{
Mihaela Grigore
}

\begin{abstract}
Purpose: Adenomyosis is a common gynecological disease that is defined as the presence of nonneoplastic ectopic endometrial glands and stroma in the myometrium. These characteristics are associated with reactive overgrowth of the musculature. The aim of this pictorial essay was to delineate the specific sonographic features of adenomyosis as seen with twodimensional (2D) and three-dimensional (3D) ultrasonography.
\end{abstract}

Methods: Evaluation of the adenomyosis is best achieved in daily practice with transvaginal ultrasonography.

Results: The most important features of adenomyosis are anechoic foci, striation, heterogeneous myometrium, and an asymmetrical uterine wall. All of these features were seen in this study by $2 \mathrm{D}$ ultrasonography. Three-dimensional ultrasonography allowed visualization of the thickness and disruption of the endometrial-myometrial junction.

Conclusion: Two-dimensional and 3D ultrasonography are valuable tools for diagnosing adenomyosis even in early stages of the disease because they make it possible to evaluate both the myometrium and the endometrial-myometrial junction. The combined information gained from the 2D and 3D ultrasonography examinations not only allows diagnosis of adenomyosis but also pinpoints the current stage of the disease.

Keywords: Adenomyosis, Endometrial-myometrial junction, Three-dimensional ultrasonography, Two-dimensional ultrasonography.

How to cite this article: Grigore M. Adenomyosis: Pictorial Essay of Two-Dimensional and Three-Dimensional Ultrasonography Findings. Donald School J Ultrasound Obstet Gynecol 2015;9(2):188-192.

\section{Source of support: Nil}

Conflict of interest: None

\section{INTRODUCTION}

Adenomyosis is a common gynecological disease defined as the presence of nonneoplastic ectopic endometrial glands and stroma in the myometrium associated with reactive overgrowth of the musculature. The incidence

Consultant

Department of Obstetrics and Gynecology, University of Medicine and Pharmacy 'Grigore T. Popa', laşi, Romania

Corresponding Author: Mihaela Grigore, Consultant, Department of Obstetrics and Gynecology, University of Medicine and Pharmacy 'Grigore T Popa', Str. Universitatii 16, Iaşi, 700115 Romania, Phone: +40 744 438024, Fax: +40 232 221516, e-mail: mihaela.grigore@edr.ro of the disease is not well known, but it is estimated to be present in 20 to $30 \%$ of the general population and up to $70 \%$ of hysterectomy specimens. ${ }^{1,2}$

Adenomyosis is not a uniform disease. Rather, it represents a spectrum of lesions, ranging from increased thickness of the endometrial-myometrial junction (EMJ) to overt adenomyosis and adenomyomas. The EMJ is the transitional zone between the mucous membrane that is the endometrium and the outer smooth muscle layer of the myometrium. Diffuse adenomyosis, which affects the entire endometrium, is the type most frequently encountered and affects the entire myometrium. Focal adenomyosis displays isolated ill-defined nodules of hypertrophic myometrium and ectopic endometrium, sometimes referred to as adenomyomas. Recent studies indicate that adenomyosis is a progressive disease whose appearance changes during the reproductive years. ${ }^{3}$ Many patients with adenomyosis are asymptomatic. When the disease is symptomatic, it is characterized by dysmenorrhea, dyspareunia, chronic pelvic pain, and menometrorrhagia. Because adenomyosis can coexist with another gynecological conditions (e.g. myoma, endometrial polyps, endometriosis), it is sometimes difficult to determine to what extent the symptomatology is caused by adenomyosis. Myometrial hypertrophy, which causes a clinically enlarged, often soft uterus, is commonly seen in conjunction with both the diffuse and focal forms. ${ }^{4}$ The final diagnosis is confirmed by pathology examination of the surgically removed uterus.

\section{Ultrasonography Findings}

Imaging techniques play an important role in the diagnosis of adenomyosis, the main diagnostic techniques being ultrasonography (US) and magnetic resonance imaging (MRI). A recent meta-analysis showed that transvaginal US and MRI have high levels of accuracy for the noninvasive diagnosis of adenomyosis. Transvaginal US had a sensitivity of $72 \%$ [ $95 \%$ confidence interval (CI) $65-79 \%$ ], specificity of $81 \%$ (95\% CI $77-85 \%$ ), positive likelihood ratio of 3.7 (95\% CI 2.1-6.4), and negative likelihood ratio of 0.3 (95\% CI 0.1-0.5). Magnetic resonance imaging had a sensitivity of $77 \%$ (95\% CI $67-85 \%$ ), specificity of $89 \%$ (95\% CI $84-92 \%)$, positive likelihood ratio of 6.5 (95\% CI 4.5-9.3), and negative likelihood ratio of 0.2 (95\% CI 0.1-0.4). ${ }^{5}$ The US technique has been 
improved steadily. The use of high-frequency transvaginal transductors improved the sensitivity and specificity of the examination.

\section{Two-dimensional Ultrasonography}

Two-dimensional (2D) US has a clearly established place in the diagnosis of adenomyosis. ${ }^{6-8}$ Many studies have compared 2D US with MRI and concluded that the former is a highly useful tool for diagnosing adenomyosis, especially in the hands of a trained sonographer. Magnetic resonance imaging is useful in difficult cases in which the US results do not definitively establish the diagnosis. ${ }^{9-11}$ The most important features of adenomyosis seen with 2D US are the following:

Uterine enlargement (Fig. 1): Uterine length may be up to $12 \mathrm{~cm}$ without a myoma inside the uterus. The borders of the uterus are usually normal (not modified by the disease). ${ }^{7,12}$

Heterogeneous myometrium with architectural disturbances (Fig. 2): Hyperechoic regions are surrounded by hypoechoic areas, which correspond to smooth muscle hyperplasia. Sakhel and Abuhamad regarded this feature as the most predictive of adenomyosis. ${ }^{12}$

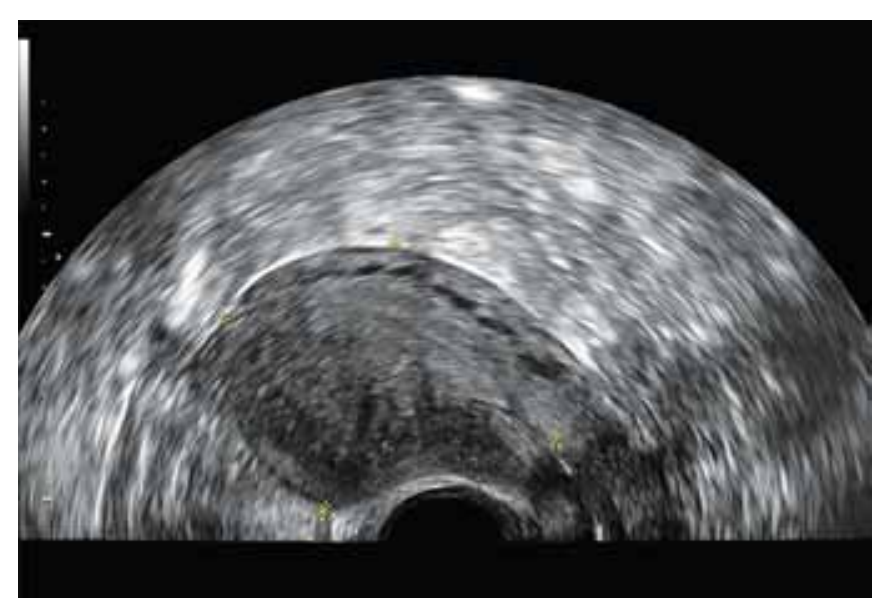

Fig. 1: Large uterus. The contour of the uterus is usually unaltered

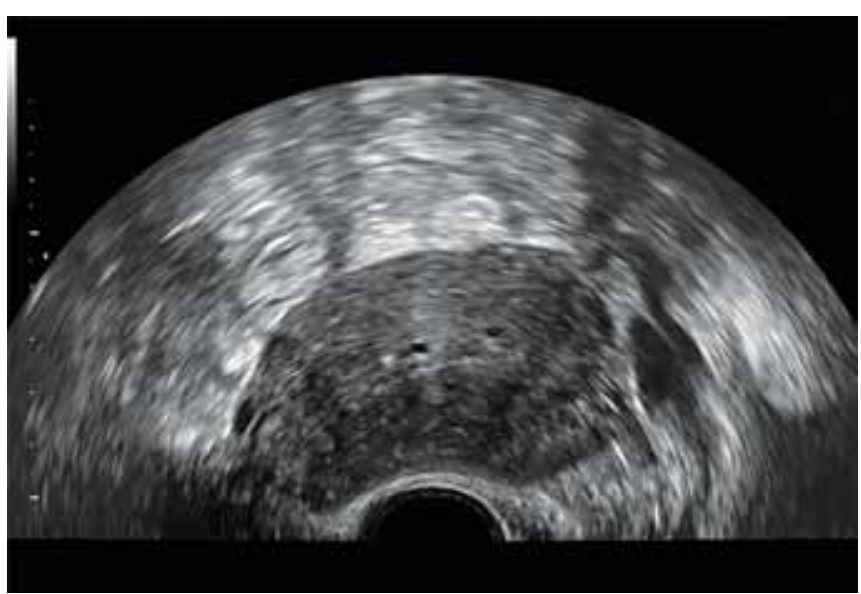

Fig. 2: Heterogenous areas within the myometrium
Asymmetrical myometrial thickening (Fig. 3): When the disease is focal, the uterine enlargement is asymmetrical. There is a difference in size between the anterior and posterior walls of the uterus in the longitudinal or transverse plane. ${ }^{13}$

Cysts of variable size throughout the myometrium (Figs 4 and 5): In most cases, cyst sizes vary by a few millimeters (1-7 $\mathrm{mm})$, although they sometimes vary as much as 2 to 4 $\mathrm{cm}$. Doppler examination is useful for differentiating anechoic images from vein dilatation. A myometrial cyst has been cited as the most specific and sensitive feature for diagnosing adenomyosis. ${ }^{12}$

Hyperechoic linear striations (Fig. 6): These striations can be seen radiating out from the endometrial surface. According to Kepkep et al the striations are the most accurate sign of adenomyosis on transvaginal US. ${ }^{14}$

Subendometrial hyperechogenic nodules: The nodules are composed of ectopic endometrium. ${ }^{8}$

Adenomyoma (Fig. 7): This lesion is a focal presence of adenomyosis and must not be misdiagnosed as a myoma. The contour of the adenomyoma is not neat. Doppler imaging shows randomly scattered vessels-in contrast to a myoma where the vessels are on the periphery. ${ }^{15,16}$ All of these sonographic features have been reported to have high sensitivity (80-87\%) and specificity (94-98\%) for distinguishing between adenomyosis and leiomyoma based on comparisons between transvaginal US and histological confirmation. ${ }^{17}$

Poor definition of the EMJ compared to that in normal uterus (Figs 8 to 10): It suggests diffuse adenomyosis and is caused by invasion of the endometrial glands in the myometrium.

Thickening of the EMJ (Figs $11 A$ and B): It appears as a hypoechoic halo around the endometrium. When associated with adenomyosis, this layer has been reported to exceed $12 \mathrm{~mm}^{12}$

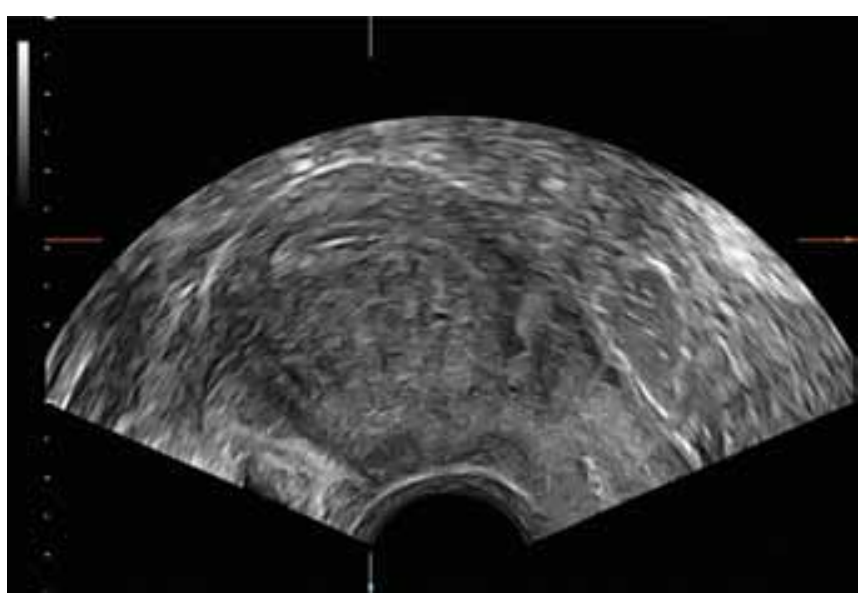

Fig. 3: Asymmetrical myometrial thickening 


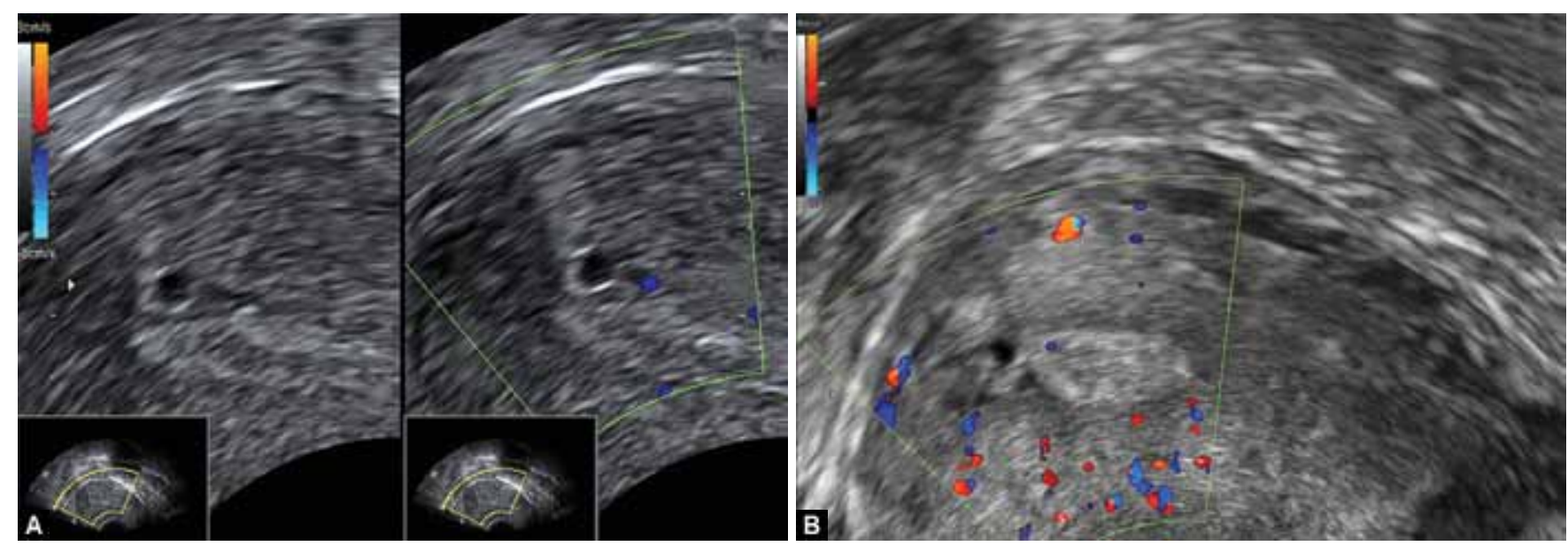

Figs $4 A$ and $B$ : Myometrial cysts

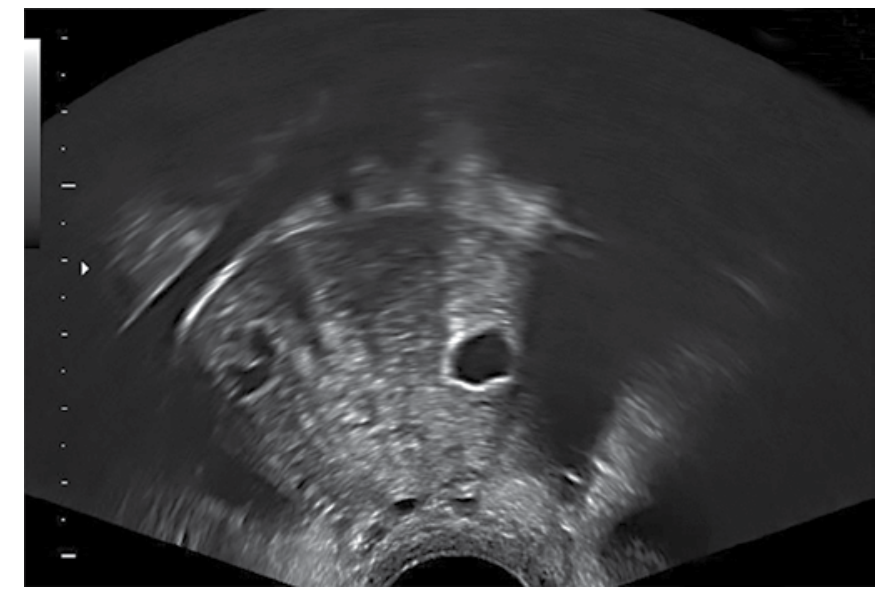

Fig. 5: Large myometrial cysts

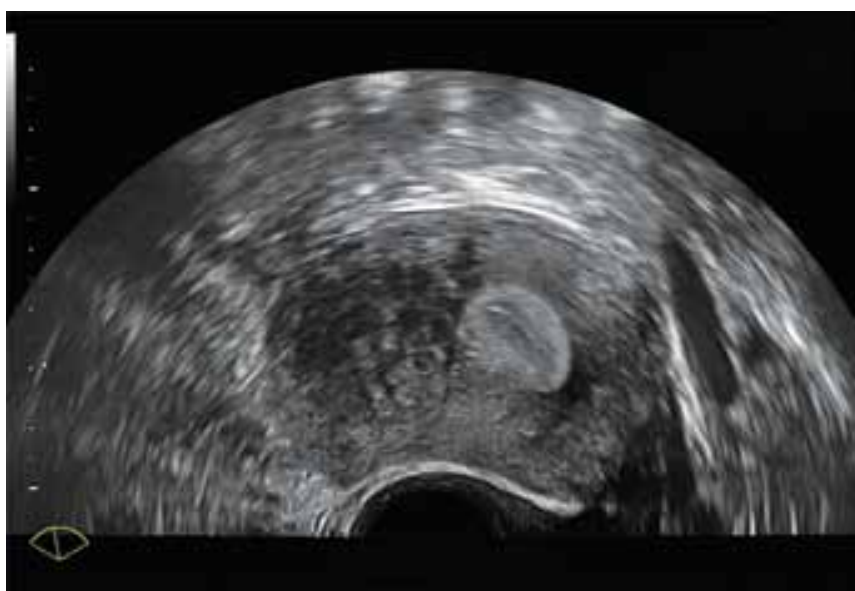

Fig. 7: Adenomyoma mass with poorly defined margins

\section{Three-dimensional Ultrasonography}

The use of three-dimensional (3D) US provided new possibilities for diagnosing gynecological disease. Its obvious advantages are that it offers more rapid, reproducible image acquisition and enhanced visualization and postprocessing capabilities. ${ }^{18}$ Three-dimensional US enables visualization of the coronal plane of the uterus and consequently gives a clear image of the EMJ. ${ }^{19}$ This

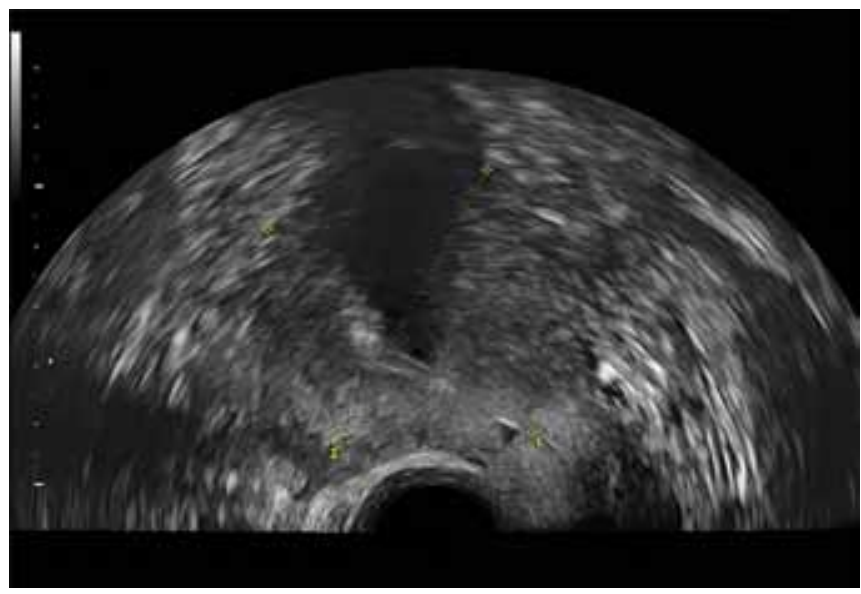

Fig. 6: Hyperechoic linear striations radiating from the endometrial surface

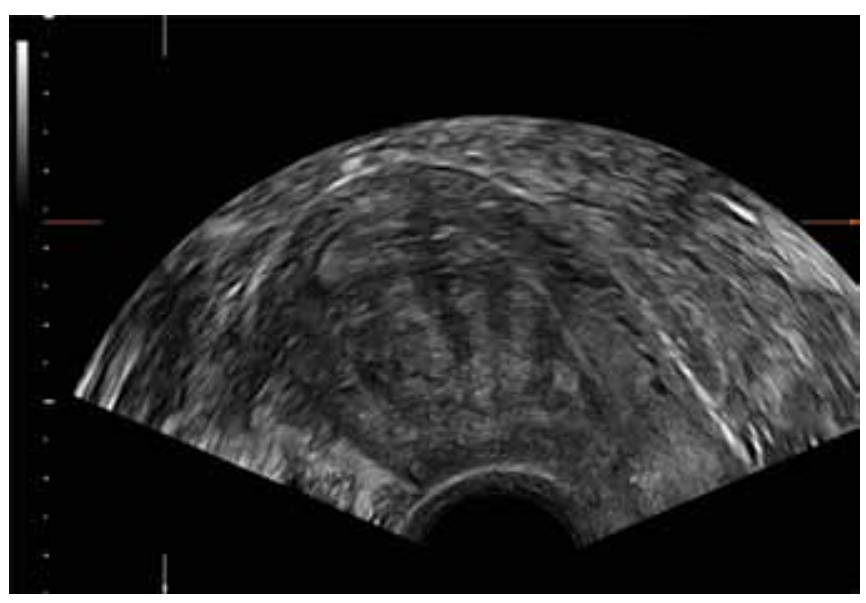

Fig. 8: Poor definition of the endometrial-myometrial junction

zone has been assigned various names in the literature: endomyometrial junctional zone, inner myometrium, uterine junctional zone, ${ }^{20}$ endometrial-subendometrial unit or stratum subvasculare, ${ }^{21}$ subendometrial myometrium ${ }^{22}$, archimetra, ${ }^{23}$ archimyometrium, ${ }^{24}$ inner myometrium..$^{25}$ Traditionally, assessment of the EMJ has been part of the MRI evaluation of the uterus, with changes in this area key to diagnosing adenomyosis. ${ }^{26}$ 


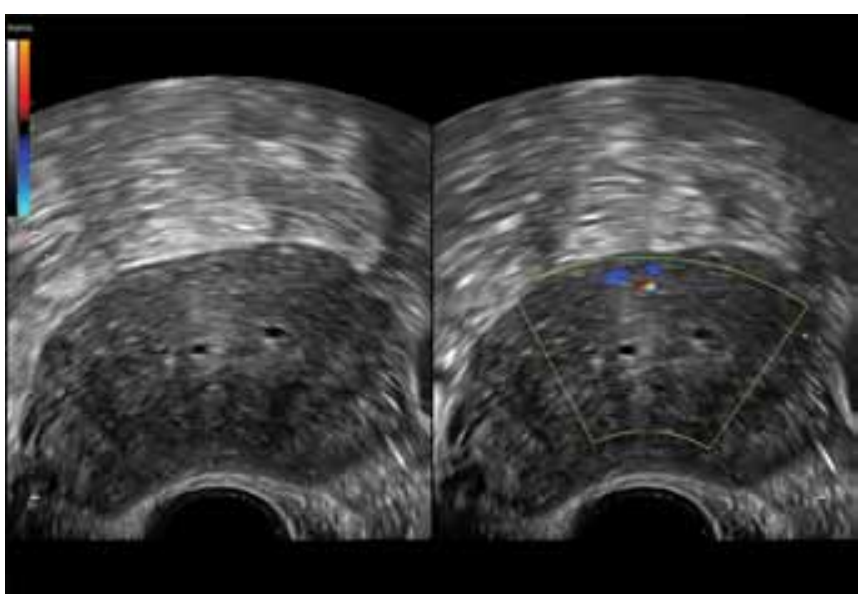

Fig. 9: Three-dimensional ultrasonography shows a normal uterus
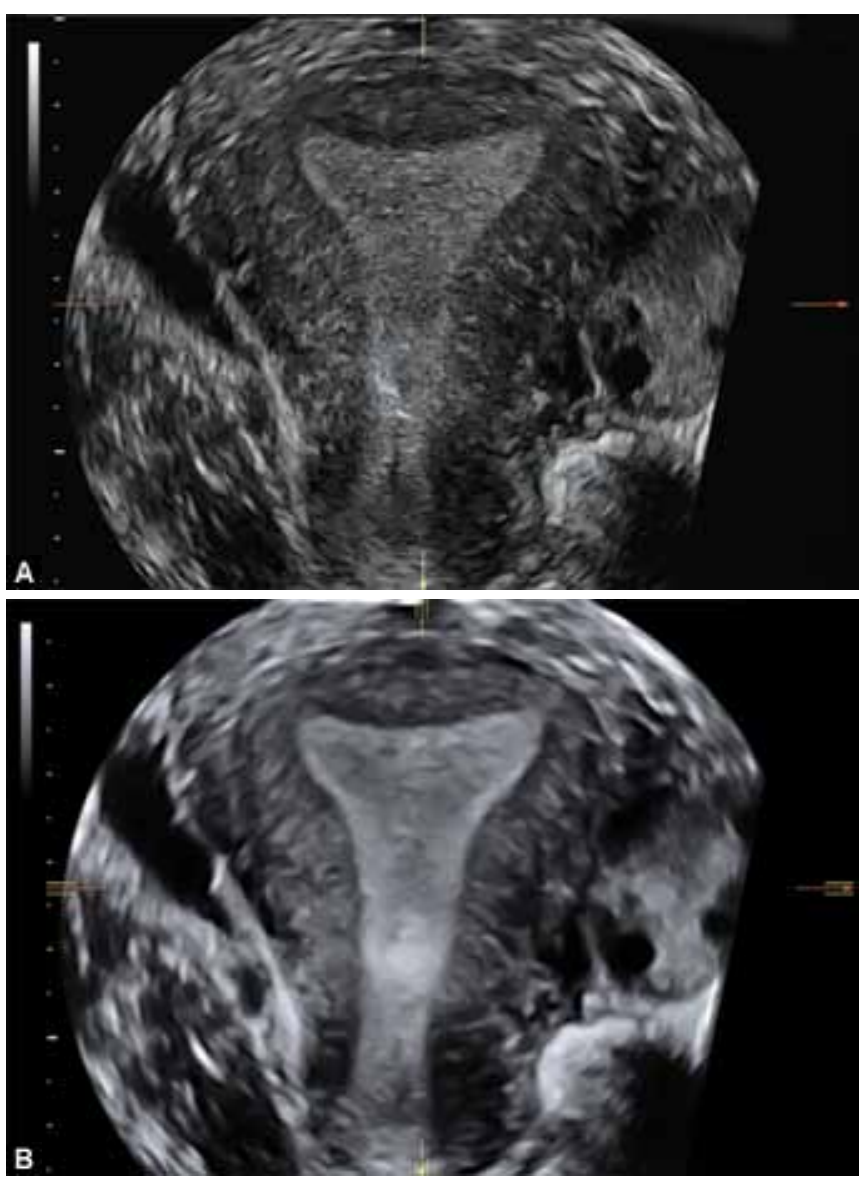

Figs $10 \mathrm{~A}$ and $\mathrm{B}$ : Three-dimensional ultrasonography with volume contrast imaging in a normal uterus

Because of the possibility of visualizing the EMJ, 3D US opens up new horizons for the diagnosis of adenomyosis. The EMJ appears on the coronal plane as a hypoechoic zone around the endometrium..$^{27}$ Adding volume contrast imaging (VCI) to the coronal plane provides a clearer view of the junctional zone (JZ). Because of the clear view with VCI, it is the modality for best analyzing and measuring the junctional zone. ${ }^{27}$ Three-dimensional US allows visualization of the lateral and fundal EMJ, which
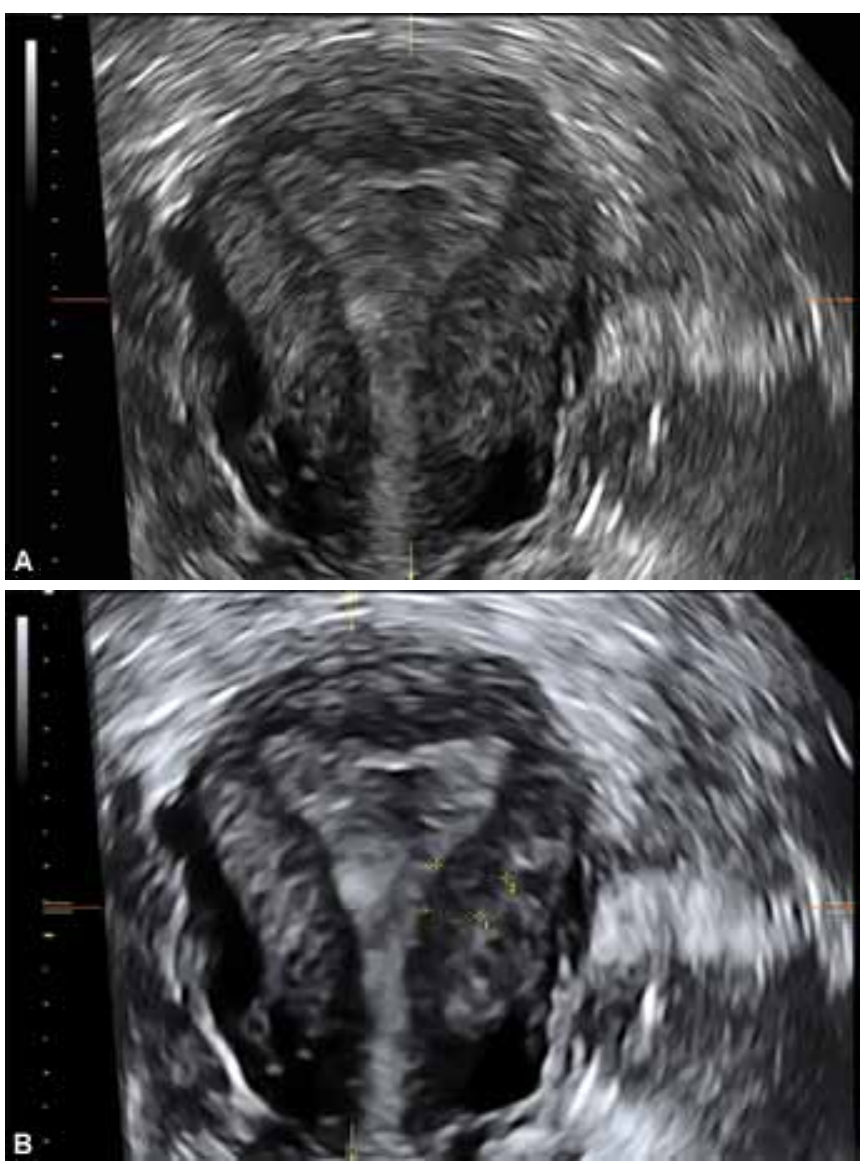

Figs 11A and B: Three-dimensional ultrasonography shows disruption of the endometrial-myometrial junction

is almost impossible to observe with $2 \mathrm{D}$ imaging. The $3 \mathrm{D}$ US features of adenomyosis are the following:

- Thickening of the EMJ: It is measured from the basal endometrium to the internal layer of the outer myometrium. A value $>8 \mathrm{~mm}$ suggests adenomyosis. ${ }^{27}$

- A difference of $>4 \mathrm{~mm}$ between the maximum and minimum EMJ values. ${ }^{27}$

- Disruption of the EMJ by infiltration of hyperechoic endometrial tissue. ${ }^{27}$

Three-dimensional US not only visualize the EMJ, it meets all the other criteria for a diagnosis of adenomyosis found with 2D US: anechoic foci, striation, heterogeneous myometrium. Also, it is believed that the features revealed by 3D US define the stage of the disease. It has been reported that changes in the thickness of the junctional zone and protrusion of the endometrium into the inner myometrium represent an early stage in the development of adenomyosis. ${ }^{19,27}$ Conventional findings, such as myometrial cysts and asymmetry of the myometrium are more likely to be signs of advanced disease. Thus, although 3D US seems to be a promising tool for diagnosing adenomyosis, further study is needed to certify our findings and especially to compare 3D US and MRI for diagnosing this disease. 
Another interesting aspect of adenomyosis is that it may play a role in infertility - it may interfere with the process of implantation. ${ }^{27,28}$ A precocious diagnosis using 2D and 3D US could perhaps initiate correct management of even asymptomatic disease with the aim of preserving fertility.

\section{CONCLUSION}

Because 2D and 3D US allow us to examine both the myometrium and the EMJ, they are valuable tools for establishing a diagnosis of adenomyosis even during early stages of the disease. The combined information gained from the 2D and 3D US examinations not only allows diagnosis of adenomyosis but also pinpoints the stage of the disease. Once clear criteria have been established for such staging, we can set up proper protocols for managing the disease.

\section{REFERENCES}

1. Azziz R. Adenomyosis: current perspectives. Obstet Gynecol Clin North Am 1998;16(1):221-235.

2. Naftalin J, Hoo W, Pateman K, Mavrelos D, Holland T, Jurkovic D. How common is adenomyosis? A prospective study of prevalence using transvaginal ultrasound in a gynaecology clinic. Hum Reprod 2012;27(12):3432-3439.

3. Gordts S, Brosens JJ, Fusi L, Benagiano G, Brosens I. Uterine adenomyosis: a need for uniform terminology and consensus classification. Reprod Biomed Online 2008;17(2):244-248.

4. Cirpan T, Yeniel O, Ulukus M, et al. Clinical symptoms and histopathological findings in subjects with adenomyosis uteri. Clin Exp Obstet Gynecol 2008;35(1):48-53.

5. Champaneria R, Abedin P, Daniels J, Balogun M, Khan KS. Ultrasound scan and magnetic resonance imaging for the diagnosis of adenomyosis: systematic review comparing test accuracy. Acta Obstet Gynecol Scand 2010;89(11):1374-1384.

6. Reinold C, Tafazoli F, Wang L. Imaging features of adenomyosis. Hum Reprod Update 1989;4(4):337-349.

7. Bromley B, Shipp TD, Benacerraf B. Adenomyosis: sonographic findings and diagnostic accuracy. J Ultrasound Med 2000;19(8):529-534.

8. Atri M, Reinhold C, Mehio AR, Chapman WB, Bret PM. Adenomyosis: US features with histologic correlation in an in vitro study. Radiol 2000;215(3):783-790.

9. Dueholm M, Lundorf E. Transvaginal ultrasound or MRI for diagnosis of adenomyosis. Curr Opin Obstet Gynecol 2007;19(6):505-512.

10. Bazot M, Darai R, Rouger J, Detchev R, Cortez A, Uzan S. Limitations of transvaginal sonography for the diagnosis of adenomyosis, with histopathological correlation. Ultrasound Obstet Gynecol 2002;20(6):605-611.
11. Dueholm M. Transvaginal ultrasound for diagnosis of adenomyosis: a review. Best Pract Res Clin Obstet Gynecol 2006; 20(4):569-582.

12. Sakhel K, Abuhamad A. Sonography of adenomyosis. J Ultrasound Med 2012;31(5):805-808.

13. Andreotti RF, Fleischer AC. The sonographic diagnosis of adenomyosis. Ultrasound Q 2005;21(3):167-170.

14. Kepkep K, Tuncay YA, Goynumer G, Tutal E. Transvaginal sonography in the diagnosis of adenomyosis: which findings are most accurate? Ultrasound Obstet Gynecol 2007;30(3): 341-345.

15. Chiang $\mathrm{CH}$, Chang MY, Hsu JJ, et al. Tumor vascular pattern and blood flow impedance in the differential diagnosis of leiomyoma and adenomyosis by color Doppler sonography. J Assist Reprod Genet 1999;16(5):268-275.

16. Botsis D, Kassanos D, Antonioc G, et al. Adenomyoma and leiomyoma: differential diagnosis with transvaginal sonography. J Clin Ultrasound 1998;26(1):21-25.

17. Fedele L, Bianchi S, Dorta M, et al. Transvaginal ultrasonography in the differential diagnosis of adenomyoma versus leiomyoma. Am J Obstet Gynecol 1992;167(3):603-606.

18. Grigore, Mare A. Applications of 3-D ultrasound in female infertility. Rev Med Chir Soc Med Nat Iasi 2009;113(4):1113-1118.

19. Naftalin J, Jurkovic D. The endometrial-myometrial junction: a fresh look at a busy crossing. Ultrasound Obstet Gynecol 2009;34(1):1-11.

20. Fusi L, Cloke B, Brosens JJ. The uterine junctional zone. Best Prac Res Clin Obstet Gynaecol 2006;20(4):479-491.

21. Noe M, Kunz G, Herbertz M, Mall G, Leyendecker G. The cyclic pattern of the immunocytochemical expression of oestrogen and progesterone receptors in human myometrial and endometrial layers: characterization of the endometrialsubendometrial unit. Hum Reprod 1999;14(1):190-197.

22. Lyons EA, Taylor PJ, Zheng XH, Ballard G, Levi CS, Kredentser JV. Characterization of subendometrial myometrial contractions throughout the menstrual cycle in normal fertile women. Fertil Steril 1991;55(4):771-774.

23. Leyendecker G, Kunz G, Noe M, Herbertz M, Mall G. Endometriosis: a dysfunction and disease of the archimetra. Hum Reprod Update 1998;4(5):752-762.

24. Leyendecker G, Kunz G, Kissler S, Wildt L. Adenomyosis and reproduction. Best Prac Res Clin Obstet Gynaecol 2006;20(4):523-546.

25. Brosens JJ, Barker FG, de Souza NM. Myometrial zonal differentiation and uterine junctional zone hyperplasia in the non-pregnant uterus. Hum Reprod Update 1998;4(5):496-502.

26. Dueholm M, Lundorf E, Hansen ES, Sorensen JS, LedertougS, Olesen F. Magnetic resonance imaging and transvaginal ultrasonography for the diagnosis of adenomyosis. Fertil Steril 2001;76(3):588-594.

27. Exacoustos C, Brienza L, Giovanni A, et al. Adenomyosis: three-dimensional sonographic findings of the junctional zone and correlation with histology. Ultrasound Obstet Gynecol 2011;37(4):471-479.

28. Campo S, Campo V, Benagiano G. Infertility and adenomyosis. Obstet Gynecol Int 2012;2012:786132. Published online26 Dec 2011. 